\title{
Editorial: Stumbling Towards Climate Justice
}

\author{
Arthur Muliro Wapakala ${ }^{1}$
}

Published online: 31 July 2017

(C) Society for International Development 2017

Stories about climate change and its unfolding effects as well as the political drama surrounding the global process to arrest it, and hopefully give humanity a chance fill the pages of our newspapers, the screens of blog posts and so on. It is fair to say that there is a growing awareness that the climate is going to be central to the future of humanity. But even as a committed bandwagon of climate deniers continues to challenge the idea that humans are responsible for global warming, they remain a minority - albeit one that is well funded and politically connected and whose agenda is ostensibly that to upend the efforts being made to arrest climate change.

But there are many sides to the stories of climate change: whereas a lot of ink is spent in describing the vicissitudes of the Paris Climate Agreement and the maneuvering around it, the stories that attract less attention are those of the human lives that have been caught up in the vortex of a changing climate. Granted, the world's media houses tend to focus on the 'big story' and more often than not, the lives of peasants in the Sahel, fisherfolk in the Bay of Bengal or First Nation peoples in the North America affected by a rapidly changing and often unpredictable climate do not make the headlines, nor do they necessarily attract the attention of the decision makers in the various global fora that are discussing the climate and what to do about it. This does not make their plight any less important: on the contrary - it is perhaps from their lives and stories that we need to begin reflecting on why urgent

Arthur Muliro Wapakala

amuliro@sidint.org

1 Rome, Italy actions are needed to try and reverse the current trajectory of global warming. Like the canary in the coal mine, their stories and experiences are perhaps a sentinel of what awaits us if we tarry in our quest. Their pleas for assistance, and most important, justice fall largely on deaf ears, perhaps because either we are convinced that their lives and livelihoods are marginal and expendable, or because we believe that by retrofitting our industries and our economies, we can continue along the same trajectory that has preoccupied our planners for pretty much the last couple of centuries. In other words, we think we can continue to maintain our current and aspired lifestyles without too much of a course correction.

If we are to survive this current challenge to our species, it can only be through a set of radical adjustments that force us back towards being in greater synchronicity with nature. But this is a difficult proposition to articulate and to swallow. Already, the much-heralded Paris Climate Agreement, whilst having obtained the signatures of over 190 countries does not challenge, or address the questions around why it became necessary to have this agreement in the first place and proceed along a path of understanding how to walk backwards from this point. Many will argue that pursuing such a path would make it impossible to have the agreement at all - and they are probably right. There are too many countries with too great a stake in the present architecture of economy and power to contemplate anything different. But then, is this not analogous to treating the symptoms of the problem and pretending that a cause does not exist? Courage needs to be found to address the root causes of the climate crisis and to discuss what we - as a species - want to do about it. To address the climate crisis, we need to talk about the prevailing models of production - but also how they are linked to inequality, discrimination and injustice around the world. In her 
article, Audrea Lim argues that the 'limitless economic growth and endless consumption that lie at the heart of capitalism' are $^{1}$ the key drivers of today's climate crisis. And she is not alone - there is a growing number of critics who excoriate the Paris approach and its silence around the need to tackle the key drivers of the climate crisis. Steffen Böhm of the University of Essex has suggested that the limitations of the current negotiation process 'result from the current 'carbon fetishism', in which even emissions are commodified in an event to maintain the economic status $\mathrm{quo}^{2}$. In this view, the elephant in the room remains 'the fundamental failure of neoliberal capitalism, as the world's dominant economic system, to confront its hunger for exponential growth of production and consumption that has been made possible by the unique energy density of fossil fuels, such as coal, oil and gas'. In his article, he refers at length to the Belgian geographer Erik Swyngedouw remarking thus:

'For him, capitalism's attempt to deal with the climate crisis is a perfect example of 'post-politics', generating a lot of talk about what needs to change to make our existence on earth sustainable - such as at the current Paris climate summit - without there much changing at all. What's important to bear in mind though is that this talk about change is not all there is. Swyngedouw also argues that capital attempts to materially reconfigure itself through the crisis of climate change, precisely by turning through the crisis of climate change, precisely by turning carbon (nature) into a commodity. And of course, this must be seen in line with the commodification processes that have always been part of capitalism's history, ${ }^{3}$

Writing about the impact of 'capitalist economics' on Indigenous peoples and communities, Kyle Powys Whyte has argued that they face climate risks largely because of how colonialism, in conjunction with capitalist economics worked to shape the geographic spaces they inhabit and subsequently their socio-economic conditions.

'The consequences of capitalist economics, such as deforestation, water pollution, the clearing of land for large scale agriculture and urbanization, generate

\footnotetext{
1 Audrea Lim, True Climate Justice Puts Communities of Color First, https://www.thenation.com/article/true-climate-justice-puts-commu nities-of-color-first/.

2 Steffen Böhm: The Paris Climate Talks and other Events of Carbon Fetishism, https://www.versobooks.com/blogs/2372-steffen-bohmthe-paris-climate-talks-and-other-events-of-carbon-fetishism.

3 Steffen Böhm: The Paris Climate Talks and other Events of Carbon Fetishism, https://www.versobooks.com/blogs/2372-steffen-bohmthe-paris-climate-talks-and-other-events-of-carbon-fetishism.
}

immediate disruptions on ecosystems, 'rapidly' rendering them very different from what they were like before, undermining Indigenous knowledge systems and Indigenous peoples' capacity to cultivate landscapes and adjust to environmental change... Yet what is more insidious about climate injustice against Indigenous peoples is that the settler institutions such as those of containment, that inflicted environmental change in the past, are the same institutions that fostered carbon-intensive economic activities on Indigenous territories. That is, containment strategies, such as removal of Indigenous peoples to reservations or the forced adoption of corporate government structures, all facilitated extractive industries, deforestation and large-scale agriculture'. (Whyte 2017)

American journalist Christian Parenti begins his book with the graphic description of the aftermath of a cattle raid in north-western Kenya and provides us with the context of this raid that left one Ekaru Loruman dead. We are told that persistent severe drought had led to encroachment of the Turkana, a pastoralist community, onto the lands of their Pokot neighbours and reciprocal raids to replenish stocks depleted by the droughts were increasingly common. He asks:

'Why did Ekaru Loruman die? [...] We could say tradition killed Ekaru, the age-old tradition of 'stocktheft', cattle raiding among the Nilotic tribes of East Africa. Or we could say he was murdered by a specific man, a Pokot from the Karasuk. Or that Ekaru was killed by the drought. When the drought gets bad, the raiding picks up. Or perhaps Ekaru was killed by forces yet larger, forces transcending the specifics of this regional drought, this raid, this geography and the Nilotic cattle cultures. To my mind... Ekaru's death was caused by the most colossal set of events in human history: the catastrophic convergence of poverty, violence and climate change'. (Parenti 2011: 4-5)

In 2015, a Dutch district court sitting in The Hague ruled that the Dutch government had a legal duty of care towards current and future generations to lower its $\mathrm{CO}_{2}$ emissions. This landmark ruling - known as the Urgenda Case - was 'the first case in which regular citizens have managed to hold their government accountable for taking insufficient action to keep them safe from dangerous climate change. The ruling stipulated that the 'Dutch government is required to reduce its emissions by at least $25 \%$ by the end of 2020 (compared to 1990 levels). This means that the Dutch government is now, effective immediately, forced to take more effective action on climate change. It is also the first case in the world in which human rights are used as a 
legal basis to protect citizens against climate change ${ }^{4}$. This case and the subsequent ruling (although under appeal by the Dutch government) has inspired similar cases in Belgium, Norway and France.

How then does the idea of justice play out henceforth? Justice for the Indigenous people who have seen their ancestral lands devastated? Or for Ekaru Loruman's family? Or those Dutch citizens who fear for this and future generations? Or for the many other cases which we have not cited? Justice, in many of our countries, is often sought and not always obtained. So why add climate justice to the pot?

Ultimately, it is because climate justice - and justice more generally - is a function of who we are and what we value. Most Western philosophers have generally regarded justice as fundamental for ordering interpersonal relations as well as establishing and maintaining a stable political society. In our case, we are perhaps more concerned with the latter part, the emphasis on having a stable political society - an outcome that is by no means guaranteed. As Peter Burnell wrote: 'If the economic adjustment costs imposed by climate change or the financial costs of mitigation and adaptation are distributed unevenly in society to the detriment of politically weak groups - the chances of reaching the democratic norm of political equality become more remote. Not just climate change but also some of the efforts to address it can lead to social injustice harming at minimum democracy's substance and reputation'. (Burnell 2012: 821)

Thus, albeit a sensible proposition, the notion of climate justice remains a thorny one to implement nonetheless. As Rebecca Hall put it:

Climate justice includes a focus on the root causes of climate change and making the systemic changes that are therefore required, a commitment to address the disproportionate burden of the climate crisis on the poor and marginalized, a demand for participatory democracy in changing these systems which require dismantling the fossil fuel corporate power structure, and a commitment to reparations and thus a fair distribution of the world's wealth. ${ }^{5}$

In his landmark Encyclical 'Laudato Sì' published in 2015, Pope Francis made an impassioned plea for climate justice suggesting that there is a need to go beyond the current palliative measures being implemented. In particular, he placed the asymmetry of power at the heart of the debate:

\footnotetext{
${ }_{4}$ The Urgenda Climate Case Explained http://www.urgenda.nl/en/ climate-case/.

5 Rebecca Hall, Defining Climate Justice, http://www.peacefulupris ing.org/defining-climate-justice-20130521.
}

'Climate change is a global problem with grave implications: environmental, social, economic, political and for the distribution of goods. It represents one of the principal challenges facing humanity in our day. Its worst impact will probably be felt by developing countries in coming decades. Many of the poor live in areas particularly affected by phenomena related to warming, and their means of subsistence are largely dependent on natural reserves and ecosystemic services such as agriculture, fishing and forestry. They have no other financial activities or resources which can enable them to adapt to climate change or to face natural disasters, and their access to social services and protection is very limited. For example, changes in climate, to which animals and plants cannot adapt, lead them to migrate; this in turn affects the livelihood of the poor, who are then forced to leave their homes, with great uncertainty for their future and that of their children. There has been a tragic rise in the number of migrants seeking to flee from the growing poverty caused by environmental degradation. They are not recognized by international conventions as refugees; they bear the loss of the lives they have left behind, without enjoying any legal protection whatsoever. Sadly, there is widespread indifference to such suffering, which is even now taking place throughout our world. Our lack of response to these tragedies involving our brothers and sisters points to the loss of that sense of responsibility for our fellow men and women upon which all civil society is founded.

Many of those who possess more resources and economic or political power seem mostly to be concerned with masking the problems or concealing their symptoms, simply making efforts to reduce some of the negative impacts of climate change. However, many of these symptoms indicate that such effects will continue to worsen if we continue with current models of production and consumption. There is an urgent need to develop policies so that, in the next few years, the emission of carbon dioxide and other highly polluting gases can be drastically reduced, for example, substituting for fossil fuels and developing sources of renewable energy'. ${ }^{6}$

This question of power asymmetries and how they are reproduced has to be a central element of climate justice campaigns going forward. We cannot talk of rethinking the current structures of production without rethinking how power within societies is managed and distributed. If the quest for climate justice is to have any success, it will need

\footnotetext{
${ }^{6}$ Encyclical Letter Laudato Sì of the Holy Father Francis on Care for Our Common Home, pp. 20-21.
} 
to embrace a broader and more radical analysis of why we are in the funk we are today, and to rethink and reimagine a different outcome. As John Riddell (referring to the North American situation, but one whose message is nonetheless universal) put it quite succinctly:

'The climate justice movement has insisted on a focus on communities most directly impacted by climate change, the marginalized and indigenous peoples. But for such an alliance to be effective it also requires building a working class environmentalism that challenges capitalist production and the endless accumulation that necessarily entails ecological degradation. Unfortunately, ecological activism in North America - even when confronting climate change - relies on market measures and utopic visions of green capitalism'. ${ }^{7}$

As Albert Einstein remarked, 'We cannot solve our problems with the same level of thinking that created them'.

So, what is the pathway that we must follow to at least try and embed climate justice at the centre of the conversations around climate change? It is necessary that we take a systemic and encompassing view that brings questions of inequality, continued oppression, gender discrimination and human rights into these conversations. This provides us with an opportunity to 'reshape our economic system, and to create real alternatives to the profit-driven, fossil fuel-dependent system of white, corporate capitalism ${ }^{8}$. And in so doing, we will also need to challenge the power centres that continue to drive global warming. This means recognizing that the vast majority of emissions today derive from industry and agribusiness. It will call for a recasting of the narrative that promotes growth and consumption at all costs.

The fact remains that there are no easy propositions or solutions. We have reached the point we are at through a prolonged and systematic period in which the primary goal of modern economic systems was growth and profit. This twin obsession neglected the ecological basis on which it thrived and it naturalized inequalities, patriarchy, violence and alienation as its core byproducts. As individuals, we might be compelled to take those actions that we believe will contribute to greater sustainability and hence be part of 'making the difference' to save the planet. Yes, these small actions are in their own right necessary and important, but this is not where we should be focusing our attention. Simple living will never be enough and will never be a substitute for the larger system change and reset that we

\footnotetext{
7 John Riddell, Climate vandalism and North American capitalism, https://johnriddell.wordpress.com/2017/06/07/climate-vandalismand-north-american-capitalism/.

8 Audrea Lim, True Climate Justice Puts Communities of Color First, https://www.thenation.com/article/true-climate-justice-puts-commu nities-of-color-first/.
}

should be craving for. So we are caught on the horns of a dilemma - one for which for most, the easier alternative is to adopt the ostrich's strategy of burying our heads in the sand and hoping that the problem will go away.

Derrick Jensen thinks we have been caught up in a double bind which he describes thus:

'A double bind is where you're given multiple options, but no matter what option you choose, you lose, and withdrawal is not an option. At this point, it should be pretty easy to recognize that every action involving the industrial economy is destructive (and we shouldn't pretend that solar photovoltaics, for example, exempt us from this: they still require mining and transportation infrastructures at every point in the production processes; the same can be said for every other so-called green technology). So if we choose option one - if we avidly participate in the industrial economy - we may in the short term think we win because we may accumulate wealth, the marker of "success" in this culture. But we lose, because in doing so we give up our empathy, our animal humanity. And we really lose because industrial civilization is killing the planet, which means everyone loses. If we choose the "alternative" option of living more simply, thus causing less harm, but still not stopping the industrial economy from killing the planet, we may in the short term think we win because we get to feel pure, and we didn't even have to give up all of our empathy (just enough to justify not stopping the horrors), but once again we really lose because industrial civilization is still killing the planet, which means everyone still loses. The third option, acting decisively to stop the industrial economy, is very scary for a number of reasons, including but not restricted to the fact that we'd lose some of the luxuries (like electricity) to which we've grown accustomed, and the fact that those in power might try to kill us if we seriously impede their ability to exploit the world - none of which alters the fact that it's a better option than a dead planet. Any option is a better option than a dead planet'.

As stated earlier, we are not left with many other options on the table other than to come up with new forms of politics that challenge the structural basis of our current economic models as well as current efforts to seek commercial opportunities in the climate crisis - which will simply be another way of continuing the ruin and disenfranchisement that have accompanied the present system to date. To return to Böhm's argument, 'climate

\footnotetext{
$\overline{9}$ Derrick Jensen, Forget Shorter Showers, https://orionmagazine.org/ article/forget-shorter-showers/.
} 
justice is not something that should come after us accepting climate capitalism. A proper just climate can only be brought about if we don't shy away from questioning the fundamental logic of carbon fetishism and the logic of the market that attempts to appropriate, commodify and financialize nature'. ${ }^{10}$ Getting to this point will require heroic efforts by women and men around the world to get out of their familiar comfort zones and, in words of Jensen, 'remember that the role of an activist is not to navigate systems of oppressive power with as much integrity as possible, but rather to confront and take down those systems'.

This journal brings together a number of viewpoints and perspectives on how questions of climate justice are seeing and addressed from different vantage points. The twentyfive contributors take us through a kaleidoscope of perspectives that taken together, give a picture of the complexity of the challenge on the one hand; and on the other, a sense of the actions and proposals that are being worked on around the world. Virtually all the authors agree that the most vulnerable victims of climate change are found in the poorest countries of the world where there is also the least capacity to put together an adequate and sufficient response to the ravages of climate change.

In her article, Miren Gutierrez gives us an overview of 'the good, the bad and the ugly'. She analyzes the politics around the commitments to the Paris Agreement and where the different signatories stand with respect to their emission targets as well as the politics around the Green Climate Fund. Julian Brave NoiseCat argues for Indigenous peoples and their knowledge regimes to be acknowledged and given a greater role in the climate mitigation process. There is a need, he argues, for indigenous rights to be broadened and strengthened in order for them to stave off the challenges coming from fossil fuel development, extractive industries and the resultant climate change. Ruth Nyambura reminds us of the persistent disconnect between the formal processes at the state level and the realities on the ground, and how this is leading to the emergence of a network of transnational climate, food and energy justice movement(s) that are working together to try and provide viable alternatives to those local communities hit by a perfect storm of multiple and intersecting crises of climate change. We are told that there is a growing and hardening fissure between the elitist narratives of climate justice and climate action and the alternative visions of society that are being nurtured and worked upon at the grassroots. Julia Puaschunder, makes a proposal as to how to how to share the benefits and burdens of climate change in a fair and just manner within society, between countries and over time. She presents and discusses

\footnotetext{
${ }^{10}$ Steffen Böhm: The Paris Climate Talks and other Events of Carbon Fetishism, https://www.versobooks.com/blogs/2372-steffenbohm-the-paris-climate-talks-and-other-events-of-carbon-fetishism.
}

innovative compensation schemes such as climate bonds to spread the burden of climate change more equally between today's and tomorrow's society. Kelly McFarland looks at environmental factors driving migration and proposes a set of 'guiding principles' that could form the basis for a new, and different conversation on the imperatives of contemporary migration and what policies might be pursued in this regard as well as some of the challenges that are likely to be faced in implementing the new policies. He decries the fact that the current political environment is ill-prepared to tackle complex, globally-based and humanitarian focused issues and challenges us to work towards building resilience within communities and to focus on the longer-term, adaptive policies geared toward slow-onset migration and urbanization. Gabriel Ferrero urges us to get behind the 2030 Development Agenda and the related Sustainable Development Goals as this, together with the Paris Agreements offers a substantive framework to deliver on climate justice and to overcome inequalities, poverty, lack of hope and the erosion of human rights, underlying root causes of insecurity, conflicts, and forced migration. He reminds us that our common destiny imposes on us the need to cultivate shared values and principles; shared goals and targets and above all shared responsibility and action by all actors. Lorna Gold challenges International Non-Governmental Development Organizations (INGDOs) not to contribute to the conspiracy of silence which still surrounds climate change in Western societies by ignoring it in their campaigns and advocacy. She argues that they have a privileged role to help shifting the public narrative on climate change and climate justice at a national level where they operate through the stories and experiences they can help leverage to bring the reality of the global scale of climate injustice into national contexts where the impacts may not be readily understood. Bertrand Noiret reflects on the challenge of ensuring food security and adequate nutrition in a world with a rapidly changing climate. He suggests that these twin goals be at the centre of climate change actions and calls for strengthened representation and participation of social movements and nongovernment organization, at relevant fora as well as closer coordination and cooperation amongst those institutions working on food security and nutrition. Tristan Quinn-Thibodeau and Brandon $\mathrm{Wu}$ reflect on the challenges that a Donald Trump presidency brings with it for NGOs and climate activists in the United States. They suggest that larger NGOs need to break out of their silos and engage with and support grassroots, frontline, and social movement leadership, fighting on issues not traditionally associated with stopping climate change. The current political context, in their view, offers a real opportunity for development NGOs to take a principled stand and actively take sides with the people they purport to serve even if these postures should prove to be uncomfortable. Isis Alvarez and Simone Lovera 
argue for the need to mainstream gender in climate change actions as this could lead to new policy actions that enhance women's participation in tackling biodiversity loss and climate change. They tell us that the patriarchal system has so far marginalized women in implementing biodiversity and climate commitments and remind us that we need to discard stereotypes of women being 'weak' and 'dependent' and recognize that historically, women have been key agents in leading societal change.

The above and the other sterling contributions in this issue challenge us collectively to reflect on the entity of the problem that climate change poses, and why ultimately, we will have to adopt a climate justice approach. As individual readers, we may not always agree with the suggestions that the authors have made or the solutions that are being implemented. Theirs are ideas to provoke conversations and to remind us that the challenges that climate change will unleash will stretch our collective imagination and test our institutions - locally and internationally in ways that perhaps they were never made to. If there is but one lesson to draw from this anthology, it is that nothing is static in a time of intense turmoil. We will look to different spheres of achievement for solutions - be they technical, social or spiritual. What we cannot do is run away from the fact that attaining climate justice; resolving the climate crisis will be in the final analysis a political challenge. In the earlier part of this editorial, I repeatedly made the point that we will need to find ways and means to go beyond the limits of the current capitalistic model of production and consumption. We will need to figure out how to challenge its foundations and to think of what can replace it - and some suggestions are made in the following articles. Wean ourselves off the dependency on fossil fuels. Tackle the waste of industrial agriculture. Rethink our models of resilience. And so on.

In concluding, we will need to find a way of ensuring that the dialogue that is necessary does not become hostage to denialism, or what David Roberts has called 'tribal epistemology' in which:

'Information is evaluated based not on conformity to common standards of evidence or correspondence to a common understanding of the world, but on whether it supports the tribe's values and goals and is vouchsafed by tribal leaders. "Good for our side" and "true" begin to blur into one'. ${ }^{11}$

The current challenge calls for collaboration, not senseless competition. It requires that we work together to enlarge the common ground from which we can begin to search for lasting solutions as opposed to creating islands of righteousness. If we are to find viable solutions and outcomes to our predicament, it will require that we find ways and means of reinforcing trust at all levels of society. This means that we will have to accept that predominant narratives are challenged and that spaces for alternative narratives are cultivated.

Many have called ours 'the age of possibilities' humanity, with its technological progress and achievements of the past centuries seemed to have reached the cusp of going beyond what were hitherto considered the limits to our progress as a species. And we have achieved a lot. But we are now discovering that nature is a powerful adversary, and not necessarily a forgiving one either.

'Never before have the possibilities of a good world for the human species as a whole been greater. At the same time, the gap between human potential and the existing conditions of humankind in its totality has probably never been wider. Ours is also an age of extremes. What stands in between the potential and the actual are the economics of environmental destruction and social exclusion of whoever is not profitable, the economics, sociology and psychology of inequality, the power politics of division and war. No end to all of this is in sight. However, a species consciousness is emerging, in particular one of environmental challenges but also of human rights and human potential'. (Therborn 2016: 37)

We are now called upon to take a step back and look at everything in perspective. A course correction may yet be possible - time is running out, but we still have a limited window to make that difference.

\section{References}

Burnell, Peter. 2012. Democracy, democratization and climate change: complex relationships. Democratization 19 (5): 813-842.

Parenti, Christian. 2011. Tropic of Chaos: Climate Change and the New Geography of Violence. New York: Nations Books.

Therborn, Göran. 2016. An Age of Progress? New Left Review No. 99 May-June.

Whyte, Kyle Powys. 2017. Is it Colonial Déjà Vu? Indigenous Peoples and Climate Injustice. In Humanities for the environment: Integrating knowledges, forging new constellations of practice, ed. J. Adamson, M. Davis, and H. Huang, 88-104. London: Earthscan Publications.

\footnotetext{
11 David Roberts, Donald Trump and the rise of tribal epistemology, https://www.vox.com/policy-and-politics/2017/3/22/14762030/ donald-trump-tribal-epistemology.
} 